This is the accepted version of a manuscript that has been uploaded to an institutional repository to meet ARC funding requirements to make this research open access.

The final version of this manuscript can be found at the journal website, Social Psychiatry and Psychiatric Epidemiology, here: https://link.springer.com/article/10.1007/s00127-016-1328-y

Please cite this article as below:

Perales F, Johnson SE, Baxter J, Lawrence D, Zubrick SR (2017) Family structure and childhood mental disorders: new findings from Australia. Social Psychiatry and Psychiatric Epidemiology. 52(4):423-433. doi:10.1007/s00127-016-1328-y 


\section{Family structure and childhood mental disorders: New findings from Australia}

Francisco Perales $^{\mathrm{a}}$, Sarah E Johnson ${ }^{\mathrm{b}}$, Janeen Baxter ${ }^{\mathrm{a}}$, David Lawrence ${ }^{\mathrm{b}, \mathrm{c}}$, Stephen R. Zubrick ${ }^{\mathrm{b}, \mathrm{c}}$

${ }^{a}$ ARC Centre of Excellence for Children and Families over the Life Course, Institute for Social Science Research, The University of Queensland, Long Pocket Precinct, 80 Meiers Rd, Building C, Indooroopilly, Brisbane QLD 4068.

${ }^{\mathrm{b}}$ ARC Centre of Excellence for Children and Families over the Life Course, Telethon Kids Institute, The University of Western Australia, 100 Roberts Road, Subiaco, Western Australia, 6008

${ }^{c}$ ARC Centre of Excellence for Children and Families over the Life Course, Graduate School of Education, The University of Western Australia, Crawley, Perth, Western Australia, 6009.

Corresponding author: Sarah Johnson. Sarah.Johnson@telethonkids.org.au; (+61) 894897715.

Acknowledgements: The authors would like to thank Rebecca Vos for research assistance. This research was supported by the Australian Research Council Centre of Excellence for Children and Families over the Life Course (project number CE140100027). The views expressed herein are those of the authors and are not necessarily those of the Australian Research Council. This study uses data from Young Minds Matter which was funded by the Australian Government Department of Health. Data collection was undertaken by Roy Morgan Research. The authors would like to thank the 6,310 families who gave their time to participate in the survey, Rajni Walia, Gerry Bardsley, the team at Roy Morgan Research, and the Survey Reference Group for their input into the design and conduct of the survey. 


\begin{abstract}
Purpose. Many children now live in non-traditional families -including one-parent, blended and step families. While a substantial body of international evidence indicates that these children display poorer cognitive and socio-emotional outcomes than children living in traditional families, research on childhood mental disorders is scarce. This report provides new evidence of the relationships between family structure and childhood mental disorders in an under-researched context, Australia.

Methods. We use recent, nationally representative data on children aged 4 to 17 from Young Minds Matter, the second Australian Child and Adolescent Survey of Mental Health and Wellbeing (N=6,310). Mental disorders were assessed using the Diagnostic Interview Schedule for Children Version IV and included social phobia, separation anxiety disorder, generalised anxiety disorder, obsessive-compulsive disorder, major depressive disorder, attention-deficit/hyperactivity disorder, and conduct disorder.

Results. Compared to children living in original families, children in one-parent, blended and step families experienced a higher prevalence of mental disorders. Amongst children whose parents separated, the time since separation was not statistically significantly related to the prevalence of mental disorders.

Conclusions. Although we are unable to assess causality, our findings highlight the strength of the association between family structure and child and adolescent mental health. They also stress the need for programs to support children, parents and families in non-traditional family types to reduce mental health inequalities in childhood and later life.
\end{abstract}

Keywords: family structure; parental separation; childhood; mental disorders; Australia 


\section{Background}

Since the 1970s, cohabitation, divorce and separation rates have become and remained high in Western societies [1]. These social processes have given rise to increasing heterogeneity in the types of families children live in while growing up, and to increasing instability in family composition. Today, a large proportion of children experience stressful life events such as divorce, separation and other forms of family breakdown before they reach adulthood. As a result, the social institution of a normative family with two biological parents is being progressively challenged, and many individuals spend some portion of their childhood living in non-traditional family forms - including one-parent families, blended families, and step families [2, 3]. Shared residence arrangements, in which children spend time in each parent's home after separation, are also on the rise in countries such as Sweden, the US and Australia [4-7]. The rise in non-traditional family forms, coupled with the fact that these families tend to have fewer resources that can be allocated to benefit child development, has led to scholastic and policy concerns about the relative development of children brought up in these family environments $[8,9]$.

Compared to children in traditional families, children in non-traditional families display lower levels of cognitive ability, including more poorly developed reading, verbal, and mathematical skills, and academic outcomes. These associations have been reported for a number of countries, including the US [10], the UK [11], Germany [12] and Sweden [3]. Children's non-cognitive abilities have also been examined revealing similar links between family type and children's socio-emotional outcomes. Children raised in non-traditional families experience slower socio-emotional development and higher rates of internalising and externalising problem behaviours than children raised in traditional families. This finding has been replicated across countries, particularly in multiple studies in the US $[10,13,14]$ and the UK $[11,15-18]$. Poor socio-emotional wellbeing amongst children has also been linked with the length of time spent in lone-parent or reconstituted families [18, $19]$ and with the number of family transitions $[10,14,18,19]$ as well as types of transition $[18,19]$. There is also evidence that children display different mental health profiles depending on their living arrangements after family breakdown. For example, children who live with both parents in a shared residence arrangement tend to have better mental health outcomes than children who live with only one of their biological parents [6].

While there is a large body of empirical evidence on how family structure and family breakdown are associated with children's mental health and socio-emotional outcomes, the mechanisms behind these associations are still contested. Many studies, particularly the earlier body of evidence, take the perspective that the experience of family breakdown leads to comparatively poor child outcomes. However, there are several plausible alternative explanations which have received some degree of support in empirical research. First, it is possible that selection effects are at play. That is, families that break down are families in which children were already struggling [13, 20-23]. Thus, the comparatively poor outcomes of children living in vulnerable families may not be the product of family breakdown itself, but of its precursors (such as poverty, material deprivation, low parental education, or poor parental mental health). Of particular importance is the possibility that poor child outcomes after family breakdown are, at least partially, due to the child witnessing marital conflict and discord preceding parental separation [9, 24-26]. Broadly, inter-parental conflict has been shown to affect children's mental health through parental emotional unavailability and poor parenting self-control, as well as through children's maladaptive coping behaviours and responses (e.g. fears, feelings of rejection, and stress) [27]. In addition, recent evidence suggests that the developmental outcomes of children in traditional and non- 
traditional families are not different after adjusting for contemporaneous family circumstances (e.g. poverty, housing, area advantage, and parental mental health) $[23,28]$. Finally, it is also possible that reverse causation is at play: coping with a child with poor mental health is a strenuous process that may lead to parental stress and conflict, and eventually to family breakdown [29, 30]. Disentangling which of these causal pathways underlies the associations between family structure and child wellbeing has been the focus of a few recent studies [13, 22, 31], but is beyond the scope of this current paper.

Research on differences in socio-emotional outcomes between children in traditional and nontraditional families has concentrated on broad measures that are generally available in population surveys, such as the Strengths and Difficulties Questionnaire, SDQ [32, 33] and the Child Behavioral Checklist, CBCL [34]. Fewer studies have considered more specific and direct measures of childhood mental disorders. This is an important oversight, as the need for intervention is clearer when these disorders are present, and treatments are available for specific disorders. Regardless of what the causal association might be, if mental disorders are more common in children living in non-traditional families this would identify groups of families that require greater support for their children, particularly as these families may have fewer resources to allocate to their children's development.

Recent studies have begun to systematically examine how growing up in a non-traditional family compared to a traditional family is associated with the prevalence of childhood mental disorders, using diagnostic interviews ${ }^{1}$. While older studies, such as the Ontario Child Health Study conducted in the 1980s, found single-parent status to be a risk factor for mental disorders in childhood and adolescence [35, 36], more recent international studies have examined rates of mental disorders across different types of non-traditional family forms. Findings from this smaller literature generally mirror those of the literature on general socioemotional development: compared to children who continuously live with both biological parents, children who live in one-parent, blended and step families as well as children who experience parental separation or divorce are more likely to suffer mental disorders. This applies to attention-deficit and hyperactivity disorders (ADHD) [37-42], depressive disorders [39], conduct disorders [37, 40, 42-44], emotional disorders [38, 40, 44], aggression and hostility disorders [41-43], and bipolar disorders and schizophrenia [39, 45]. The limited available evidence however, relates to just a handful of North American [37, 39, 43] and European [38, 40-42, 44-47] countries.

In Australia, recent research has established links between family structure and children's socioemotional outcomes. For example, Lucas et al. [28] used nationally-representative data from the Longitudinal Study of Australian Children (LSAC) and found that 8-9 year-old children in separated families exhibited poorer

\footnotetext{
${ }^{1}$ We undertook a systematic search for literature on the links between family structure and childhood mental disorders in academic repositories (e.g., Scopus, Web of Knowledge). The search terms we used included permutations of the terms 'anxiety', 'attention deficit', 'CBCL', 'depression', 'depressive symptoms', 'Diagnostic Interview Schedule for Children', 'disorder', 'disruptive behaviour', 'distress', 'hyperactivity' 'mental health', 'social phobia' in combination with the terms 'family structure', 'family breakdown', 'family instability', 'parental separation', 'divorce', and 'family type'. We searched within the articles' title, abstract and keywords. The systematic search yielded 186 items. Upon closer inspection, a vast majority of these did not meet the necessary criteria. In most cases, this was because the studies examined broad measures of socioemotional outcomes, such as the SDQ and the CBCL. Only the 11 papers we cite here were confirmed to assess the links between family structure and childhood mental disorders using diagnostic interviews or equivalent clinical assessments.
} 
mental health, as measured by the SDQ, than children in original families. Also using LSAC data, Perales et al. [23] found that children who spent some time outside an original family before age 5 had comparatively worse socio-emotional outcomes, as measured by the SDQ and its different subscales. Australian evidence on the impact of family structure on childhood mental disorders is scarce. Using data from the first Australian child and adolescent survey of mental health and wellbeing, Sawyer et al. [48] reported bivariate results showing a higher prevalence of mental disorders (depressive disorder, conduct disorder and ADHD) in step, blended and one-parent families than in original families. A study by Hayatbakhsh et al. [49] using the Mater-University of Queensland cohort study found that young adults from Queensland whose parents were separated by age 14 exhibited a greater prevalence of problem behaviours and poorer mental health by age 21, whereas Heckel and colleagues [50-52] found that in a Sydney sample parental separation was associated with increased severity of symptoms amongst children suffering from ADHD.

In this paper, we examine the relationship between family structure and childhood mental disorders in Australia, using recent, high quality, nationally representative data on children aged 4 to 17 from the 2013/2014 Young Minds Matter survey. The richness of the Young Minds Matter data enables us to follow a finer-grained approach when categorizing family structure, differentiating between original, blended, step and one-parent families -instead of simply splitting families into 'couple families' and 'one-parent families', as in most previous Australian studies. This is important, as simple categorizations of family structure may conceal important differences in child outcomes. Based on the extant literature on the relationships between family structure and children's health and wellbeing outcomes, our guiding hypothesis is that a lower proportion of children living in traditional families experience mental disorders compared with children living in other family types. For children whose parents separated, the Young Minds Matter data also enable us to test whether the time since separation was associated with the prevalence of mental disorders. As the associated empirical evidence is scarcer and mixed (see discussion below), we make no specific hypothesis concerning the direction of the association between time since separation and the prevalence of child mental disorders.

\section{Method}

Data source

Young Minds Matter is the second Australian Child and Adolescent Survey of Mental Health and Wellbeing. Full details of the survey methodology have been published elsewhere [53]. Briefly, a national survey of the parents and carers of children and adolescents aged between 4 and 17 years was undertaken. Where a household had more than one child in this age range, one child was randomly selected to participate in the study. Survey data were collected from the primary carer of the survey child by means of face-to-face interviews conducted in the home. The response rate to the household survey was 55\%, with a final responding sample of 6,310 families with children aged 4-17 years. Data collection took place between May 2013 and April 2014.

\section{Measures}

Mental disorders: Mental disorders were assessed using the Diagnostic Interview Schedule for Children Version IV (DISC-IV) [54, 55]. The DISC-IV applies full diagnostic criteria to determine if the child or adolescent had a mental disorder in the previous 12 months as specified in the Diagnostic and Statistical Manual for Mental Disorders Version IV [56]. Seven disorder modules were used in the survey and administered to primary carers. 
These included four anxiety disorders -social phobia, separation anxiety disorder, generalised anxiety disorder, and obsessive-compulsive disorder, as well as major depressive disorder, ADHD and conduct disorder. For the purpose of this paper, the four anxiety disorders were combined into one category,

Family structure: Families were classified according to the Australian Bureau of Statistics family blending classification variable, which aims to broadly represent different stages of family change and reformation:

- One-parent families

- Original families in which all children are the natural, adopted or foster child of both partners in the couple and there are no step children.

- $\quad$ Step families have at least one resident step child, but no child who is the natural or adopted child of both partners.

- Blended families have two or more children; at least one child who is the natural or adopted child of both parents, and at least one who is the step child of one of them.

- Other families have no children who are the natural, adopted, foster or step child of either parent or carer. These include families with children being raised by their grandparents or other relatives.

Young Minds Matter did not collect information on the residency arrangements of children whose parents separated, which prevented us from testing whether these made a difference to children's mental disorders.

Where it was identified from the relationship grid that the primary carer of the survey child was one of the child's original parents but the other original parent was not in the household, the parent was asked why they were no longer living with the child's other original parent. Possible responses included parental separation, parental death, and the other parent working away from home, being in custody, or being temporarily absent. In the majority of the households where only one original parent was present, this was due to the parents having separated. In these households, the primary carer was asked how long ago the separation occurred.

Control variables: In our multivariate analyses we control for child's age at the time of the interview, child's sex, and household income. Concerning the latter, primary carers were asked to report their pre-tax annual household income from all sources, using income categories aligned with those in the 2011 Australian Census of Population and Housing. Household income was grouped into three discrete categories: \$130,000 or more per year (approximately the top quartile of the income distribution), \$52,000-\$129,999 per year (the middle 50\%), and less than $\$ 52,000$ per year (the bottom quartile). Around $4 \%$ of primary carers either did not know or refused to provide their household income. These cases were retained within a 'not stated' category in the analyses.

\section{Statistical analysis}

The survey data were weighted to represent the full Australian population of 4-17 year-olds, and to adjust for non-response patterns. In particular, families with children aged 7 years or under or with more than one child aged 4-17 years were found to be more likely to participate in the survey. The weighting accounts for this. Survey estimates of the prevalence of mental disorders and their associated confidence intervals have been calculated using the Taylor Series Linearisation method [57]. Logistic regression was used to examine the multivariate relationships between family structure, time since separation and the prevalence of mental disorder. This analysis was conducted using the SAS SURVEYLOGISTIC procedure to account for the clustered nature of the sample design and the use of survey weights. All analyses were conducted using SAS software [58]. 


\section{Results}

\section{Univariate statistics}

The sample prevalence of any mental disorder, based on parent report, was $13.9 \%$, with $6.9 \%$ of children experiencing anxiety disorders or ADHD, 3.3\% experiencing major depressive disorder, and 1.8\% experiencing conduct disorders (Table 1). Weighted figures have been reported previously [59].

Of all children in the sample, $68.6 \%$ lived in original families with both original parents, $19.8 \%$ lived in one-parent families, $6.2 \%$ lived in blended families, $4.5 \%$ lived in step families, and the remaining $0.9 \%$ lived in households with other family structures (Table 1).

\section{TABLE 1 HERE}

\section{Bivariate analyses}

The prevalence of mental disorders was significantly lower in original families compared with other family types (Table 2). The prevalence of any disorder was $10.4 \%$ in original families (95\% CI: 9.4\%-11.5\%), compared with $18.3 \%$ in step families (95\% CI: $12.9 \%-23.7 \%$ ), $20.2 \%$ in blended families (95\% CI: $15.9 \%-$ $24.4 \%$ ), and $22.4 \%$ in one-parent families $(19.7 \%-25.1 \%)$. Due to small numbers, the prevalence of disorders was not separately estimated for other family types.

A similar pattern was observed for each of the individual mental disorders considered (Table 2). The prevalence of each of the mental disorders was statistically significantly higher among one-parent families compared with original families but not exclusively so. A higher prevalence of mental disorders was also observed amongst children in step and in blended families compared with children in original families, although the observed differences were not always statistically significant.

\section{TABLE 2 HERE}

In families where the original parents had separated, there was no evidence of differences in the rate of childhood mental disorders by the time since separation (Table 3). No pattern was observed in either younger or older children.

\section{TABLE 3 HERE}

To allow for the possibility that there might be non-linear associations between the prevalence of mental disorders, child's age, and time since separation, we used generalised additive models to fit a non-linear regression model. This is a non-parametric method that makes no prior assumption about the shape of the relationship between the variables. These analyses reveal that differences in the prevalence of mental disorders between original families and families where the original parents had separated were smallest for the youngest children (Figures 1-3). However, there was no evidence of any association between time since separation and the prevalence of childhood mental disorders.

\section{Multivariate analyses}

Multivariate logistic regression modelling confirmed the associations between family structure and the prevalence of childhood mental disorders, adjusting for sex and age of child, and household income (Table 4). Among children living in families with both original parents in the household, the prevalence of disorders was higher in blended families compared with original families (OR 2.56, 95\% CI: 1.58-4.14). Similar odds ratios 
were identified across categories of time since separation in separated families, again finding no association between time since separation and the prevalence of disorders. In families where neither original parent was present in the household, the odds that the child experienced a mental disorder were substantially higher (OR 3.62, 95\% CI: 2.35-5.59).

\section{TABLE 4 HERE}

\section{Sensitivity analyses}

Two sets of sensitivity analysis were conducted. First, we found no significant difference in the rates of mental disorders in the context of blended families according to whether the child was a biological, adopted or fostered child of both parents $(22.1 \%$; $95 \%$ CI: $14.0-30.2 \%)$ or just one of the parents $(19.3 \%$; $95 \%$ CI: $14.3-24.4 \%)$. Second, including a measure of primary-carer mental-health status (self-report of ever being diagnosed with a mental disorder) in our multivariate models resulted in a modest reduction of odds ratios on the likelihood of the child having a mental disorder (any disorder or each type) by family type and time since separation. However, all odds ratios that were statistically significant remained so with adjustment for primary carer mental health. Because we are unable to identify whether the diagnosed mental disorder occurred before or after family breakdown, we prefer not to retain this variable in our main models.

\section{Discussion and conclusion}

In this paper we have examined whether and how family structure is associated with the prevalence of childhood mental disorders amongst children aged 4 to 17 years in Australia. We contribute to the scarce Australian literature by using recent, nationally representative, high-quality data from Young Minds Matter, the Second Australian Child and Adolescent Survey of Mental Health and Wellbeing (N=6,310), and by considering mental disorders instead of broader socio-emotional outcomes. In addition, we add to the emerging international literature by examining these associations in a new country context, Australia.

Our results indicate that there are substantial and statistically significant differences in the prevalence of mental disorders amongst Australian children who live in different family types. As posed in our guiding hypothesis, children in original families (also referred to as 'traditional', 'normative', 'intact' or 'biological' families in the literature) are about half as likely as children in step, blended or one-parent families to experience any mental disorder. Differences in the prevalence of mental disorder between children in original families and children in other families remain in multivariate models that adjust for child's sex, child's age and household income. The prevalence of mental disorders is not statistically different for children in one-parent families, children in blended families, and children in step families. Hence, our results do not support "traditional" social narratives arguing that children in one-parent families carry the highest burden of morbidity.

These results are consistent with prior Australian evidence indicating that children in traditional families experience better socio-emotional outcomes than children in other family types, as measured by 'broad' instruments such as the SDQ [23, 28]. While short measures of social and emotional problems such as the SDQ are associated with mental health problems, they lack the specificity of diagnostic interviews. Our focus on specific mental disorders, captured by the Diagnostic Interview Schedule for Children Version IV, reveals that family structure is not just associated with markers of childhood problem behaviours. Both internalising disorders such as anxiety disorders and major depressive disorder, and externalising disorders, such as ADHD and conduct disorder, were more common in children living in step, blended or one-parent families. Our results 
are also consistent with international evidence reporting links between family structure and childhood mental disorders [37-47]. While the few available studies have focused on countries such as Canada, the US, or the Nordic countries, our research confirms that the patterns of association found in those national contexts also operate in contemporary Australia. Hence, our findings add to cumulative evidence indicating that, while national contexts may moderate its influence, living outside an original family is related to children's mental health problems.

We also contributed to the scarce literature on the associations between family structure and childhood mental disorders by examining whether time since parental separation is associated with the prevalence of mental disorders. Our results provide little evidence that this is the case. There is currently no scholarly consensus on whether children's socio-emotional and mental health outcomes are affected by the time lapse since parental separation: some studies find that children recover to some extent, others find that children's outcomes get progressively worse, while others find no association (see Størksen et al., 2006 and references therein) [60]. We did however find that differences in the prevalence of mental disorders between children in original families compared to those in different family types were smallest amongst the youngest children, especially in respect to anxiety and depressive disorders. This could be due to lower parental recognition of symptoms, or mild symptoms with lower impact on functioning. Therefore, differences in the prevalence of mental disorders by family type may be less evident at this young age. We can speculate that, as children commence school, teachers are able to identify symptoms not previously identified by parents. Pearce and colleagues did not find a sensitive period in which exposure to reconstituted or lone-parent families had particularly pernicious effects on children's socio-emotional outcomes. Although they found that cumulative exposure to reconstituted or lone-parent families (combined) was associated with more behavioural problems, this was largely explained by confounders and the experience of poverty after family breakdown [18]. Our study modestly contributes to shifting the weight of the evidence towards no association. However, our data are 'truncated' at age 17, and so our analyses do not consider whether and how the association between family breakdown and mental disorders evolves as individuals move into young adulthood.

While our findings are important, our results need to be interpreted with caution. The data that we leverage, despite being unique in many ways, are cross-sectional. This means that our results cannot be taken as evidence that family structure produces children's mental disorders, or vice versa [22]. Other factors not assessed in the survey may also account for some of the observed associations. For instance, children in families which split up may be exposed to more or more intense (unmeasured) negative circumstances prior to the family breakdown, such as parental mental health problems, family dysfunction, conflict and abuse, as well as poorer socio-economic conditions [22, 23, 28]. These findings suggest that the consequences that family breakdown has on different life domains (such as household income or parental mental health) are more likely to lie behind the comparatively poor mental health observed amongst children in vulnerable families. Although we included a measure of primary carer mental health in sensitivity analysis, the greater risk of mental disorders in families having experiencing breakdown was still significant. It is likely this variable was not specific enough in terms of the timing of the diagnosis vis-a-vis the family breakdown, the severity of the disorder, and its impact on family relationships. Disentangling these mechanisms would require panel data on family structure and childhood mental disorders, which are unfortunately unavailable. 
Bearing in mind these methodological caveats, our finding that family breakdown is related to a higher prevalence of childhood mental disorders and that this association does not diminish over time has significant implications for policy and practice. Mental disorders in childhood and adolescence can be persistent and disabling, and impact on children's development, including adversely impacting educational attainment [61, 62]. In addition, the majority of adult mental disorders have first onset in childhood or adolescence, and mental disorders have been identified as a factor contributing to the intergenerational transmission of adversity [63]. Hence, our findings highlight the importance of putting in place both preventive and remedial policies aimed at closing the gaps in mental health across different family forms. Interventions that may help children living in non-traditional families include parenting programs, or direct support for young people through programs and services. For instance, the Positive Parenting Program (Triple P) [64] has been shown to reduce the incidence of behavioural disorders such as ADHD and conduct disorder. headspace has been designed to provide support to young people aged 12-15 years experiencing a range of mental health problems and challenging life circumstances including family breakup and family conflict $[65,66]$.

Future studies in the field may refine our findings in several ways. First, by leveraging panel data to investigate the longitudinal associations between family structure and childhood mental disorders, new studies could yield estimates that are closer to causal effects. Second, further research may benefit from measuring childhood mental disorders through direct clinical assessments, as parental reports such as those used here may be prone to measurement error and report bias [67]. Third, a promising avenue for future research is to more systematically investigate the protective factors that promote resilience to mental health issues amongst children raised in non-traditional family types [68]. Such analyses would benefit from incorporating contextual factors, such as those pertaining to the school or neighbourhood environment at the meso level, and the national context at the macro level. Finally, as new data become available, future research should examine the impact on childhood mental disorders of emerging living arrangements for children in non-traditional families, such as shared residence [4-7].

To conclude, our research provides robust evidence of links between the type of family in which children grow up and the prevalence of mental disorder amongst children. While our findings constitute an important step forwards in the Australian context and complement the available international evidence, more research on these issues is required to fully understand these processes and inform evidence-based policies aimed at redressing their effects on children.

\section{Ethical approval}

The research protocol for Young Minds Matter was approved by the Australian Government Department of Health Human Research Ethics Committee, and The University of Western Australia Human Research Ethics Committee. The protocol for this study was approved by The University of Western Australia Human Research Ethics Committee. All research has been undertaken in accordance with Australia's National Statement on Ethical Conduct in Human Research.

\section{Conflict of interest statement}

On behalf of all authors, the corresponding author states that there is no conflict of interest. 


\section{References}

1. Lesthaeghe R (2014) The second demographic transition: a concise overview of its development. P Natl Acad Sci USA 111(51):18112-18115

2. Bumpass L, Raley RK (1995) Redefining single-parent families: cohabitation and changing family reality. Demography 32:97-109

3. Björklund A, Ginther D, Sundström M (2007) Family structure and child outcomes in the USA and Sweden. J Popul Econ 20:183-201

4. Bergström M, Modin B, Fransson E, Rajmil L, Berlin M, Gustafsson PA, Hjern A (2013) Living in two homes-a Swedish national survey of wellbeing in 12 and 15 year olds with joint physical custody. BMC Public Health 13868 http://www.biomedcentral.com/1471-2458/13/868

5. Melli M, Brown P (2008) Exploring a new family form - The shared time family. Int J Law Policy Family 22: $231-269$

6. Nielsen L. (2014) Shared physical custody: summary of 40 studies on outcomes for children. J Divorce Remarriage, 55(8), 613-635

7. Sodermans AK, Matthijs K (2014) Joint physical custody and adolescents' subjective well-being: A personality x environment interaction. J Fam Psychol 28(3): 346-356

8. McLanahan S, Percheski C (2008) Family structure and the reproduction of inequalities. Annu Rev Sociol 34:257-276

9. Waldfogel J, Craigie TA, Brooks-Gunn J (2010) Fragile families and child wellbeing. The Future Child 20(2):87-112

10. Carlson M, Corcoran M (2001) Family structure and children's behavioral and cognitive outcomes. J Marriage Fam 63(3):779-792

11. Kiernan KE, Mensah FK (2009) Poverty, maternal depression, family status and children's cognitive and behavioural development in early childhood: a longitudinal study. J Soc Policy 38(04):569-588

12. Francesconi M, Jenkins SP, Siedler T (2010) Childhood family structure and schooling outcomes: evidence for Germany. J Popul Econ 23(3):1073-1103

13. Amato PR, Anthony CJ (2014) Estimating the effects of parental divorce and death with fixed effects models. J Marriage Fam 76(2):370-386

14. Fomby P, Cherlin AJ (2007) Family instability and child well-being. Am Sociol Rev 72(2):181-204

15. Dunn J, Deater-Deckard K, Pickering K, O’Connor TG, Golding J (1998) Children's adjustment and prosocial behaviour in step-, single-parent, and non-stepfamily settings: findings from a community study. J Child Psychol Psyc 39(8):1083-1095

16. McMunn AM, Nazroo JY, Marmot MG, Boreham R, Goodman R (2001) Children's emotional and behavioural well-being and the family environment: findings from the Health Survey for England. Soc Sci Med 53(4):423-440

17. Pearce A, Lewis H, Law C (2013) The role of poverty in explaining health variations in 7-year-old children from different family structures: findings from the UK Millennium Cohort Study. J Epidemiol Commun $\mathrm{H}$ 67;181-189

18. Pearce A, Hope S, Lewis H, Law C (2014) Family structure and socio-emotional wellbeing in the early years: a life course approach. Longit Life Course Stud 5(3): 263-282 
19. Magnuson K, Berger L (2009) Family structure, states and transitions: associations with children's wellbeing during middle childhood. J Marriage Fam 71(3), 575-591

20. Ginther DK, Pollak RA (2004) Family structure and children's educational outcomes: Blended families, stylized facts, and descriptive regressions. Demography 41:671-696

21. Hofferth SL (2006) Residential father family type and child well-being: investment versus selection. Demography 43:53-77

22. McLanahan S, Tach L, Schneider D (2013) The causal effects of father absence. Ann Rev Sociol 399:399427

23. Perales F, O’Flaherty M, Baxter J (2015) Early life course family structure and children's socio-emotional development: a view from Australia. Child Ind Res. doi: 10.1007/s12187-015-9356-9

24. Cherlin AJ, Furstenberg FF, Chase-Lansdale PL, Robins PK, Morrison DR, Tietler JO (1991) Longitudinal studies of effects of divorce on children in Great Britain and the United States. Science 252:1386-1389

25. Morrison DR, Coiro MJ (1999) Parental conflict and marital disruption: do children benefit when highconflict marriages are dissolved? J Marriage Fam 61:626-637

26. Sun Y. Family environment and adolescents' well-being before and after parents' marital disruption: a longitudinal analysis (2001) J Marriage Fam 63:697-713

27. Cummings EM, Davies PT (2002) Effects of marital conflict on children: recent advances and emerging themes in process-oriented research. J Child Psychol Psyc 43:31-63

28. Lucas N, Nicholson JM, Erbas B (2013) Child mental health after parental separation: the impact of resident/non-resident parenting, parent mental health, conflict and socioeconomics. J Fam Stud 19(1):53-69

29. Bzostek S, Beck A. Working Paper 08-11-FF. Center for Research on Child Wellbeing; Princeton: 2008. Family structure and child health outcomes in fragile families

30. Wymbs BT, Pelham WE, Molina BSG, Gnagy EM, Wilson WK, Greenhouse JB (2008) Rate and predictors of divorce among parents of youth with ADHD. J Consult Clin Psychol 76(5):735-744

31. Lee D, McLanahan S (2015) Family structure transitions and child development instability, selection, and population heterogeneity. Am Sociol Rev 80(4):783-763.

32. Goodman R (1997) The strengths and difficulties questionnaire: a research note. J Child Psychol Psyc 38(5):581-586

33. Goodman R (2001) Psychometric properties of the strengths and difficulties questionnaire. J Am Acad Child Psy 40(11):1337-1345

34. Achenbach TM, Rescorla LA (2001) Manual for the ASEBA School-Age Forms and Profiles. Burlington, VT: University of Vermont, Research Center for Children, Youth, and Families.

35. Munroe-Blum H, Boyle MH, Offord DR (1988) Single-parent families: child psychiatric disorder and school performance. J Am Acad Child Adolesc Psychiatry 27(2):214-219

36. Offord DR, Boyle MH, Fleming JE, Munroe-Blum H, Grant NI (1989) Ontario Child Health Study: summary of selected results. Can J Psychiaty 34(6):483-91

37. Bramlett MD, Blumberg SJ (2007) Family structure and children's physical and mental health. Health Affair 26(2):549-558 
38. Carballo JJ, García-Nieto R, Álvarez-García R, Caro-Cañizares I, López-Castromán J, Muñoz-Lorenzo L, de Leon-Martinez V, Baca-García E (2013) Sibship size, birth order, family structure and childhood mental disorders. Soc Psych Psych Epid 48(8):1327-1333

39. Cuffe SP, McKeown RE, Addy CL, Garrison CZ (2005) Family and psychosocial risk factors in a longitudinal epidemiological study of adolescents. J Am Acad Child Psy 44(2):121-129

40. Meltzer H (2007) Childhood mental disorders in Great Britain: An epidemiological perspective. Child Care in Practice 13(4):313-326

41. Rydell A-M (2010) Family factors and children's disruptive behaviour: an investigation of links between demographic characteristics, negative life events and symptoms of ODD and ADHD. Soc Psych Psych Epid 45(2):233-244

42. Stenmark H, Bergstrom E, Hagglof B, Ohman A, Petersen S (2016) Mental problems and their sociodemographic determinants in young school children in Sweden, a country with high gender and income equality. Scand J Public Healt 44(1):18-26

43. Bornovalova MA, Blazei R, Malone SH, McGue M, Iacono WG (2013) Disentangling the relative contribution of parental antisociality and family discord to child disruptive disorders. Personality Disorders: Theory, Research, and Treatment 4(3):239-246

44. Heiervang E, Stormark KM, Lundervold AJ, Heimann M, Goodman R, Posserud M-B et al (2007) Psychiatric disorders in Norwegian 8- to 10-year-olds: an epidemiological survey of prevalence, risk factors, and service use. J Am Acad Child Psy 46(4): 438

45. Paksarian D, Eaton WW, Mortensen PB, Merikangas KR, Pedersen CB (2015) A population-based study of the risk of schizophrenia and bipolar disorder associated with parent-child separation during development. Psychol Med 45(13):2825-2837

46. Björkenstam E, Burström B, Vinnerljung B, Kosidou K (2016) Childhood adversity and psychiatric disorder in young adulthood: an analysis of 107,704 Swedes. J Psychiat Res 77:67-75

47. Paananen R, Ristikari T, Merikukka M, Gissler M (2013) Social determinants of mental health: a Finnish nationwide follow-up study on mental disorders. J Epidemiol Commun H 67(12):1025-1031

48. Sawyer MG, Arney FM, Baghurst PA et al (2000) Mental health of young people in Australia. Mental Health and Special Programs Branch, Commonwealth Department of Health and Aged Care.

49. Hayatbakhsh R, Clavarino AM, Williams GM, Bor W, O'Callaghan MJ, Najman JM (2013) Family structure, marital discord and offspring's psychopathology in early adulthood: a prospective study. Eur Child Adoles Psy 22(11):693-700

50. Heckel L, Clarke A, Barry R, McCarthy R, Selikowitz M (2009a) The relationship between divorce and the psychological well-being of children with ADHD: differences in age, gender, and subtype. Emot Behav Diffic 14(1):49-68

51. Heckel LD, Clarke AR, Barry RJ, McCarthy R, Selikowitz M (2009b) The relationship between divorce and children with $\mathrm{AD} / \mathrm{HD}$ of different subtypes and comorbidity: results from a clinically referred sample. J Divorce Remarriage 50(6):427-443

52. Heckel L, Clarke AR, Barry RJ, McCarthy R, Selikowitz M (2013) Child AD/HD severity and psychological functioning in relation to divorce, remarriage, multiple transitions and the quality of family relationships. Emot Behav Diffic 18(4):353-373 
53. Hafekost J, Lawrence D, Boterhoven de Haan K et al (2015) Methodology of the second Australian Child and Adolescent Survey of Mental Health and Wellbeing. Aust NZ J Psychiat 50(9):866-875

54. Fisher PW, Shaffer D, Paicentini JC, Lapkin J, Kafantaris V, Leonard H, Herzog DB (1993) Sensitivity of the Diagnostic Interview Schedule for Children, 2nd edition (DISC-2.1) for specific diagnoses of children and adolescents. J Am Acad Child Psy 32:666-673

55. Shaffer D, Fisher P, Lucas C, Dulcan MK, Schwab-Stone ME (2000) NIMH Diagnostic Interview Schedule for Children, Version IV (NIMH DISC-IV): description, differences from previous versions and reliability of some common diagnoses. J Am Acad Child Psy 39:28-38

56. American Psychiatric Association (2000). Diagnostic and Statistical Manual of Mental Disorders, Fourth Edition, Text Revision. Washington, DC: American Psychiatric Association.

57. Wolter KM (2007) Introduction to variance estimation, Second Edition. New York: Springer.

58. SAS Institute Inc (2014) SAS/STAT Software, Version 9.4. Cary, NC: SAS Institute Inc.

59. Lawrence D, Johnson S, Hafekost J et al (2015) The Mental Health of Children and Adolescents: Report on the Second Australian Child and Adolescent Survey of Mental Health and Wellbeing. Department of Health, Canberra.

60. Størksen I, Røysamb E, Holmen TL, Tambs K (2006) Adolescent adjustment and well-being: effects of parental divorce and distress. Scand J Psychol 47(1):75-84

61. Patel V, Flisher AJ, Hetrick S, McGorry P (2007) Mental health of young people: a global public-health challenge. Lancet 369:1302-1313

62. Patton GC, Coffey C, Romaniuk H, Mackinnon A, Carlin JB, Degenhardt L, Olsson CA, Moran P (2014) The prognosis of common mental disorders in adolescents: a 14-year prospective cohort study. Lancet 383:1404-1411

63. Wickrama KA, Conger RD, Abraham WT (2005) Early adversity and later health: the intergenerational transmission of adversity through mental disorder and physical illness. J Gerontol B Psychol Sci Soc Sci 60:125-9

64. Stallman HM, Sanders MR (2014) A randomized controlled trial of Family Transitions Triple P: a groupadministered parenting program to minimize the adverse effects of parental divorce on children. J Divorce Remarriage 55(1):33-48

65. Rickwood DJ, Telford NR, Mazzer KR, Parker AG, Tanti CJ, McGorry PD (2015a) The services provided to young people through the headspace centres across Australia. Med J Australia 202: 533-536

66. Rickwood DJ, Mazzer KR, Telford NR, Parker AG, Tanti CJ, McGorry PD (2015b) Changes in psychological distress and psychosocial functioning in young people visiting headspace centres for mental health problems. Med J Australia 202:537-542

67. Eaton WW, Neufeld K, Chen L, Cai G (2000) A comparison of self-report and clinical diagnostic interviews for depression: diagnostic interview schedule and schedules for clinical assessment in neuropsychiatry in the Baltimore Epidemiologic Catchment Area Follow-Up. Arch Gen Psychiat 391; 57(3):217-22

68. Weaver JM, Schofield TJ (2015) Mediation and moderation of divorce effects on children's behavior problems. J Fam Psychol 29(1):39-48 
Table 1: Sample characteristics for analytical sample $(\mathrm{N}=6,310)$

\begin{tabular}{|c|c|c|}
\hline & $\mathrm{n}$ & $\%$ \\
\hline \multicolumn{3}{|l|}{ Sex- } \\
\hline Male & 3,254 & 51.6 \\
\hline Female & 3,056 & 48.4 \\
\hline \multicolumn{3}{|l|}{ Age group- } \\
\hline 4-11 years & 3,334 & 52.8 \\
\hline $12-17$ years & 2,976 & 47.4 \\
\hline \multicolumn{3}{|l|}{ Family structure- } \\
\hline Original family & 4,331 & 68.6 \\
\hline Step family & 283 & 4.5 \\
\hline Blended family & 392 & 6.2 \\
\hline One-parent family & 1,250 & 19.8 \\
\hline Other family & 54 & 0.9 \\
\hline \multicolumn{3}{|c|}{ Number of biological parents in household- } \\
\hline 0 & 132 & 2.1 \\
\hline 1 & 1,754 & 27.8 \\
\hline 2 & 4,424 & 70.1 \\
\hline \multicolumn{3}{|l|}{ Household income- } \\
\hline Less than $\$ 52,000$ per year & 1,479 & 23.4 \\
\hline$\$ 52,000-\$ 129,999$ per year & 2,833 & 44.9 \\
\hline$\$ 130,000$ or more per year & 1,686 & 26.7 \\
\hline Not stated & 312 & 4.9 \\
\hline \multicolumn{3}{|c|}{ Reason why not with child's other biological parent- } \\
\hline Separated & 1,308 & 20.7 \\
\hline Other & 335 & 5.3 \\
\hline Not stated & 111 & 1.8 \\
\hline \multicolumn{3}{|l|}{ Time since separation- } \\
\hline $0-2$ years & 232 & 3.7 \\
\hline $2-5$ years & 328 & 5.2 \\
\hline 5-10 years & 420 & 6.7 \\
\hline More than 10 years & 300 & 4.8 \\
\hline Not stated & 28 & 0.4 \\
\hline \multicolumn{3}{|l|}{ Mental disorder ${ }^{\mathrm{a}}$} \\
\hline Anxiety disorder & 438 & 6.9 \\
\hline Major depressive disorder & 205 & 3.3 \\
\hline ADHD & 434 & 6.9 \\
\hline Conduct disorder & 116 & 1.8 \\
\hline Any disorder & 870 & 13.8 \\
\hline
\end{tabular}

${ }^{\mathrm{a} C h i l d r e n ~ m a y ~ m e e t ~ d i a g n o s t i c ~ c r i t e r i a ~ f o r ~ m o r e ~ t h a n ~ o n e ~ d i s o r d e r ~}$ 
Table 2: Prevalence of mental disorder by family structure

\begin{tabular}{|c|c|c|c|c|c|}
\hline Mental disorder ${ }^{\mathrm{a}}$ & & $\begin{array}{c}\text { Original } \\
\text { family } \\
(\mathrm{n}=4,331)\end{array}$ & $\begin{array}{c}\text { Step } \\
\text { family } \\
(\mathrm{n}=283)\end{array}$ & $\begin{array}{l}\text { Blended } \\
\text { family } \\
(\mathrm{n}=392)\end{array}$ & $\begin{array}{c}\text { One-parent } \\
\text { family } \\
(\mathrm{n}=1,250)\end{array}$ \\
\hline \multirow{2}{*}{ Anxiety disorder } & $\%$ & 4.7 & $9.3 *$ & $9.0 *$ & $12.9 *$ \\
\hline & $95 \% \mathrm{CI}$ & $(4.0-5.4)$ & $(5.4-13.2)$ & $(5.9-12.1)$ & $(10.7-15.1)$ \\
\hline \multirow{2}{*}{ Major depressive disorder } & $\%$ & 1.7 & $4.7 *$ & 3.5 & $5.5 *$ \\
\hline & $95 \% \mathrm{CI}$ & $(1.3-2.1)$ & $(2.0-7.4)$ & $(1.6-5.5)$ & $(4.2-6.8)$ \\
\hline \multirow{2}{*}{ ADHD } & $\%$ & 5.7 & 7.9 & $13.4 *$ & $11.1 *$ \\
\hline & $95 \% \mathrm{CI}$ & $(4.9-6.5)$ & $(4.3-11.6)$ & $(9.6-17.3)$ & $(9.1-13.1)$ \\
\hline \multirow{2}{*}{ Conduct disorder } & $\%$ & 1.0 & $4.4 *$ & $3.4 *$ & $4.8 *$ \\
\hline & $95 \% \mathrm{CI}$ & $(0.7-1.3)$ & $(1.2-7.7)$ & $(1.4-5.5)$ & $(3.4-6.3)$ \\
\hline \multirow{2}{*}{ Any disorder } & $\%$ & 10.4 & $18.3 *$ & $20.2 *$ & $22.4 *$ \\
\hline & $95 \% \mathrm{CI}$ & $(9.4-11.5)$ & $(12.9-23.7)$ & $(15.9-24.4)$ & $(19.7-25.1)$ \\
\hline
\end{tabular}

${ }^{\mathrm{a}}$ Children may meet diagnostic criteria for more than one disorder

*significantly higher than the prevalence amongst children living in original families at $p=0.05$ 
Table 3: Prevalence of mental disorders in children living in families where the original parents have separated, by time since separation and child's age

\begin{tabular}{|c|c|c|c|c|c|c|}
\hline \multirow[b]{2}{*}{ Time since separation } & \multicolumn{2}{|c|}{ 4-11 years } & \multicolumn{2}{|c|}{$12-17$ years } & \multicolumn{2}{|c|}{ 4-17 years } \\
\hline & $\%$ & $95 \% \mathrm{CI}$ & $\%$ & $95 \% \mathrm{CI}$ & $\%$ & $95 \% \mathrm{CI}$ \\
\hline \multicolumn{7}{|c|}{ Anxiety disorders } \\
\hline Less than 2 years & 9.6 & $(4.5-14.7)$ & 14.1 & $(6.1-22.0)$ & 11.0 & $(6.7-15.3)$ \\
\hline $2-5$ years & 9.8 & $(5.1-14.5)$ & 14.6 & $(6.7-22.5)$ & 11.7 & $(7.0-16.3)$ \\
\hline $5-10$ years & 15.1 & $(9.1-21.1)$ & 10.8 & $(6.6-15.1)$ & 12.9 & $(9.1-16.7)$ \\
\hline 10 years or more & & & 11.3 & $(7.1-15.4)$ & 10.7 & $(6.7-14.6)$ \\
\hline \multicolumn{7}{|c|}{ Major depressive disorders } \\
\hline Less than 2 years & 3.0 & $(0.0-5.9)$ & 13.7 & $(5.7-21.7)$ & 6.4 & $(3.0-9.8)$ \\
\hline $2-5$ years & (a) & & 8.6 & $(2.9-14.4)$ & 3.5 & $(1.2-5.8)$ \\
\hline $5-10$ years & 4.4 & $(1.0-7.7)$ & 7.6 & $(3.9-11.2)$ & 6.0 & $(3.5-8.5)$ \\
\hline 10 years or more & & & 9.3 & $(5.8-12.8)$ & 8.8 & $(5.5-12.2)$ \\
\hline \multicolumn{7}{|c|}{ ADHD } \\
\hline Less than 2 years & 9.3 & $(4.8-13.7)$ & (a) & & 7.8 & $(4.4-11.3)$ \\
\hline $2-5$ years & 10.6 & $(5.8-15.4)$ & 14.3 & $(7.2-21.4)$ & 12.0 & $(7.4-16.6)$ \\
\hline 5 - 10 years & 14.9 & $(9.8-20.0)$ & 9.3 & $(4.8-13.8)$ & 12.0 & $(8.4-15.5)$ \\
\hline 10 years or more & & & 10.1 & $(6.4-13.7)$ & 10.0 & $(6.4-13.5)$ \\
\hline \multicolumn{7}{|c|}{ Conduct disorders } \\
\hline Less than 2 years & (a) & & (a) & & 3.5 & $(0.9-6.0)$ \\
\hline $2-5$ years & 7.6 & $(3.4-11.7)$ & (a) & & 5.7 & $(3.0-8.4)$ \\
\hline $5-10$ years & 3.9 & $(0.8-6.9)$ & 3.5 & $(0.5-6.5)$ & 3.7 & $(1.5-5.8)$ \\
\hline 10 years or more & & & 5.2 & $(1.9-8.5)$ & 5.0 & $(1.8-8.1)$ \\
\hline \multicolumn{7}{|c|}{ Any disorder ${ }^{\mathrm{a}}$} \\
\hline Less than 2 years & 18.3 & (11.7-24.9) & 22.7 & $(13.1-32.2)$ & 19.7 & $(14.3-25.1)$ \\
\hline 2 - 5 years & 18.0 & $(12.0-23.9)$ & 24.6 & $(15.5-33.8)$ & 20.5 & $(14.8-26.3)$ \\
\hline 5 - 10 years & 24.9 & (18.0-31.8) & 21.6 & $(15.6-27.6)$ & 23.2 & $(18.6-27.8)$ \\
\hline 10 years or more & & & 21.3 & $(16.2-26.4)$ & 20.7 & $(15.7-25.6)$ \\
\hline
\end{tabular}

${ }^{\mathrm{a}}$ Children may meet diagnostic criteria for more than one disorder (a) Too few to report. 
Table 4: Likelihood of child having a mental disorder, by selected characteristics of the family $(\mathrm{N}=6,310)$

\begin{tabular}{|c|c|c|c|c|c|c|c|c|c|c|}
\hline & \multicolumn{2}{|c|}{$\begin{array}{l}\text { Anxiety } \\
\text { disorders }\end{array}$} & \multicolumn{2}{|c|}{$\begin{array}{l}\text { Major depressive } \\
\text { disorders }\end{array}$} & \multicolumn{2}{|c|}{ ADHD } & \multicolumn{2}{|c|}{$\begin{array}{l}\text { Conduct } \\
\text { disorders }\end{array}$} & \multicolumn{2}{|c|}{$\begin{array}{c}\text { Any } \\
\text { disorder }^{\mathrm{a}}\end{array}$} \\
\hline & OR & $95 \% \mathrm{CI}$ & OR & $95 \% \mathrm{CI}$ & OR & $95 \% \mathrm{CI}$ & OR & $95 \% \mathrm{CI}$ & OR & $95 \% \mathrm{CI}$ \\
\hline \multicolumn{11}{|l|}{$\begin{array}{l}\text { Number of biological parents living in } \\
\text { household- }\end{array}$} \\
\hline \multicolumn{11}{|l|}{ Two biological parents- } \\
\hline Original family & 1 & 1 & 1 & 1 & 1 & 1 & 1 & 1 & 1 & 1 \\
\hline Blended family & 2.32 & $(1.22-4.41)$ & 1.81 & $(0.57-5.67)$ & 2.84 & $(1.57-5.13)$ & 2.97 & $(0.85-10.38)$ & 2.56 & $(1.58-4.14)$ \\
\hline \multicolumn{11}{|l|}{$\begin{array}{l}\text { One biological parent (step, blended } \\
\text { or one-parent family) - }\end{array}$} \\
\hline \multicolumn{11}{|l|}{$\begin{array}{l}\text { Reason not with other biological } \\
\text { parent- }\end{array}$} \\
\hline \multicolumn{11}{|l|}{ Separated- } \\
\hline \multicolumn{11}{|l|}{ Time since separation- } \\
\hline Less than 2 years & 2.21 & $(1.36-3.62)$ & 4.36 & $(2.35-8.07)$ & 1.16 & $(0.67-2.02)$ & 2.94 & $(1.22-7.07)$ & 1.89 & $(1.29-2.77)$ \\
\hline $2-5$ years & 2.30 & $(1.42-3.73)$ & 2.05 & $(0.96-4.38)$ & 1.77 & $(1.09-2.86)$ & 4.57 & $(2.44-8.53)$ & 1.87 & $(1.27-2.73)$ \\
\hline $5-10$ years & 2.46 & $(1.68-3.60)$ & 2.81 & $(1.67-4.73)$ & 1.84 & $(1.27-2.65)$ & 3.19 & $(1.53-6.66)$ & 2.09 & $(1.57-2.77)$ \\
\hline More than 10 years & 2.16 & $(1.38-3.39)$ & 2.59 & $(1.61-4.16)$ & 2.19 & $(1.39-3.43)$ & 5.21 & $(2.32-11.66)$ & 2.00 & $(1.43-2.79)$ \\
\hline Other/Not stated & 2.01 & $(1.40-2.87)$ & 1.48 & $(0.79-2.76)$ & 1.88 & $(1.33-2.64)$ & 4.07 & $(2.19-7.58)$ & 1.85 & $(1.42-2.40)$ \\
\hline None & 3.85 & $(2.17-6.81)$ & 3.36 & $(1.74-6.48)$ & 2.42 & $(1.30-4.53)$ & 9.16 & $(4.31-19.49)$ & 3.62 & $(2.35-5.59)$ \\
\hline Controls $^{b}$ & & & & & & & & & & \\
\hline
\end{tabular}

${ }^{\mathrm{a} C h i l d r e n ~ m a y ~ m e e t ~ d i a g n o s t i c ~ c r i t e r i a ~ f o r ~ m o r e ~ t h a n ~ o n e ~ d i s o r d e r ~}$

bModels also adjust for household income, child's sex, and child's age in single year 
Fig 1: Predicted probability that the child has a mental disorder, by child's age and time since parents separated

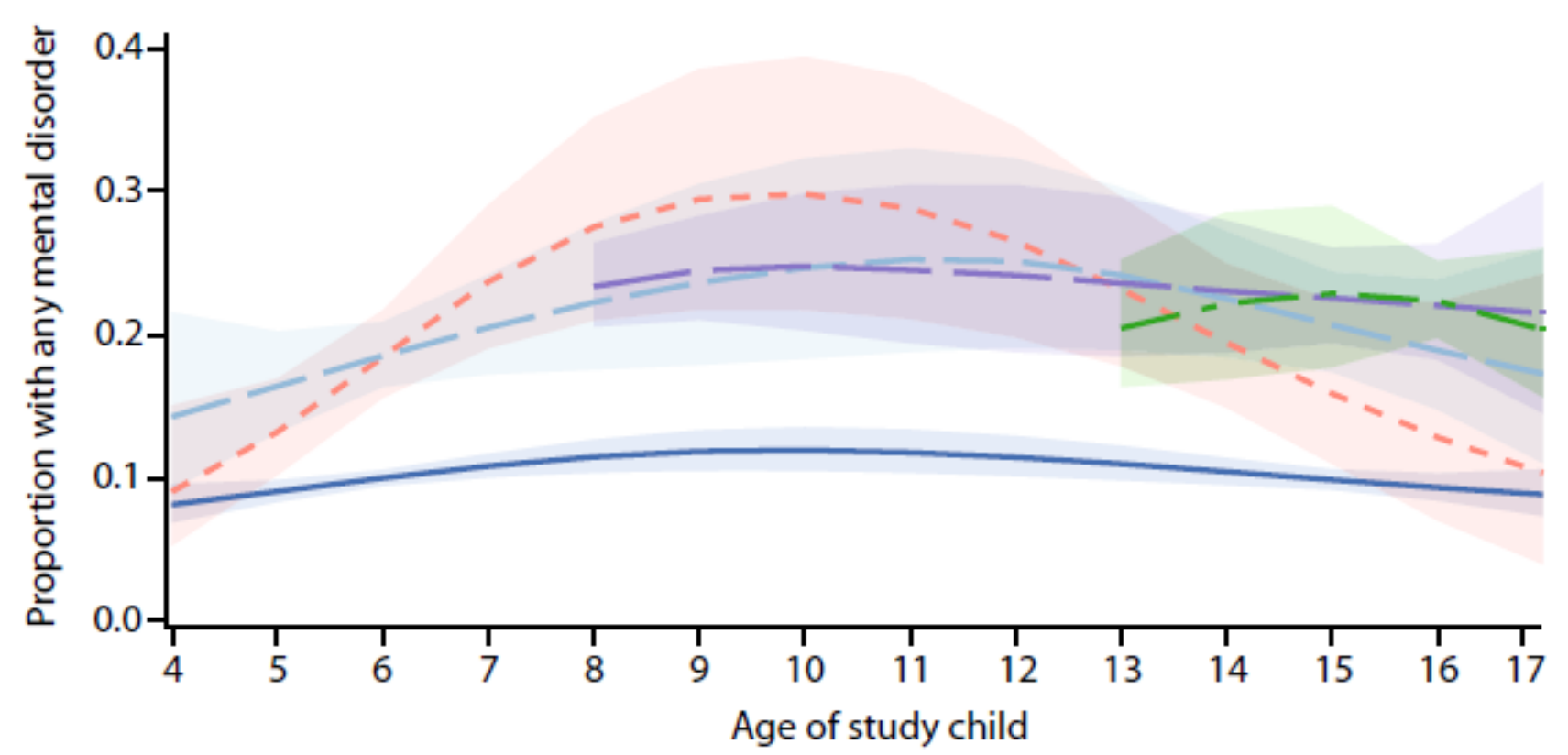

Time since separation (with $95 \%$ confidence limits)

Lives with both original parents $-\ldots--$ Less than 2 years

- 2-5 years $\quad-$ 5-10years

- - 10 years or more 
Fig 2: Predicted probability that the child has an anxiety or major depressive disorder, by child's age and time since parents separated

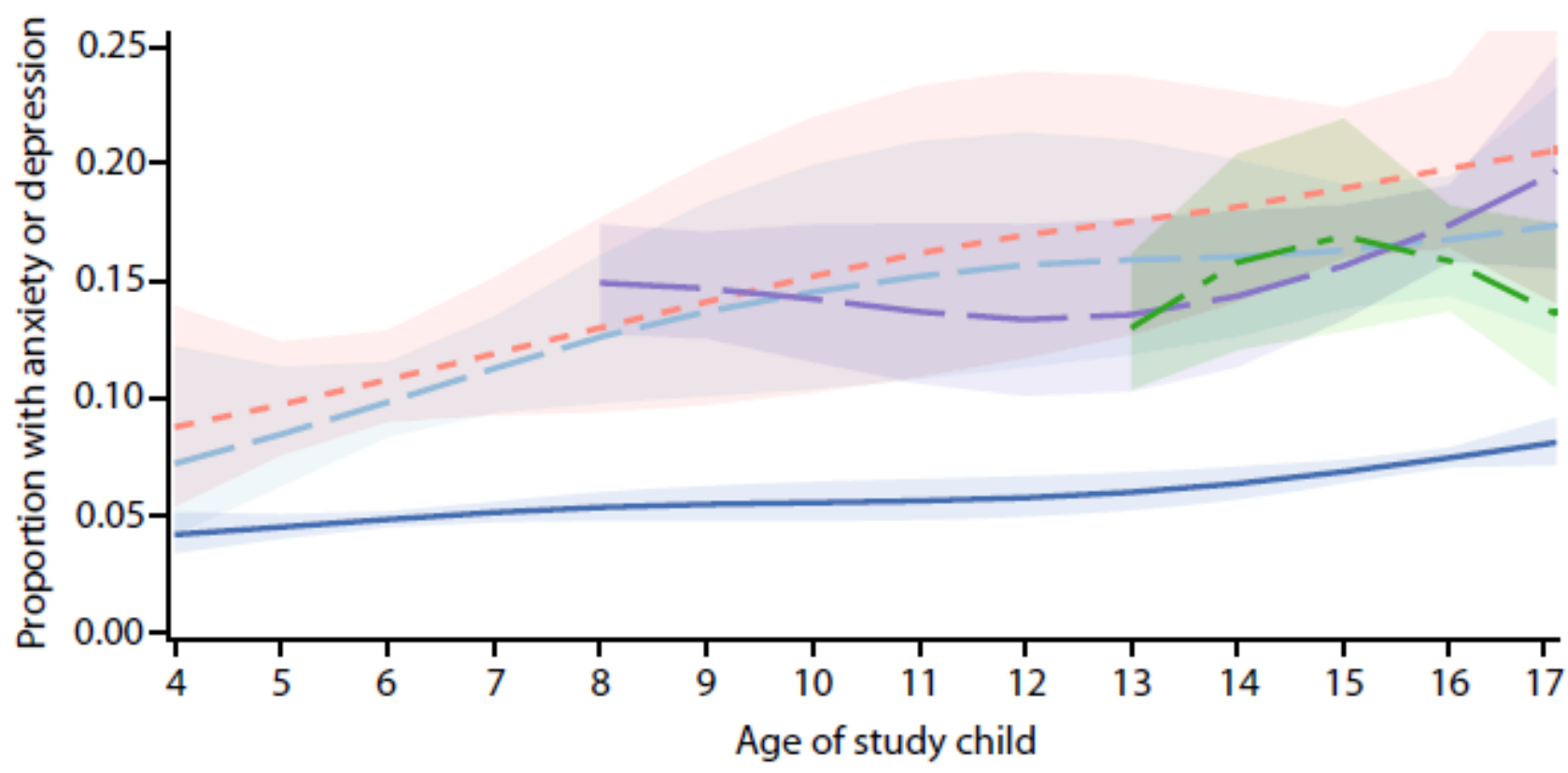

Time since separation (with $95 \%$ confidence limits)

Liveswith both original parents - - - - Less than 2 years

- 2-5 years - 5-10 years

- - 10 years or more 
Fig 3: Predicted probability that the child has ADHD or a conduct disorder, by child's age and time since parents separated

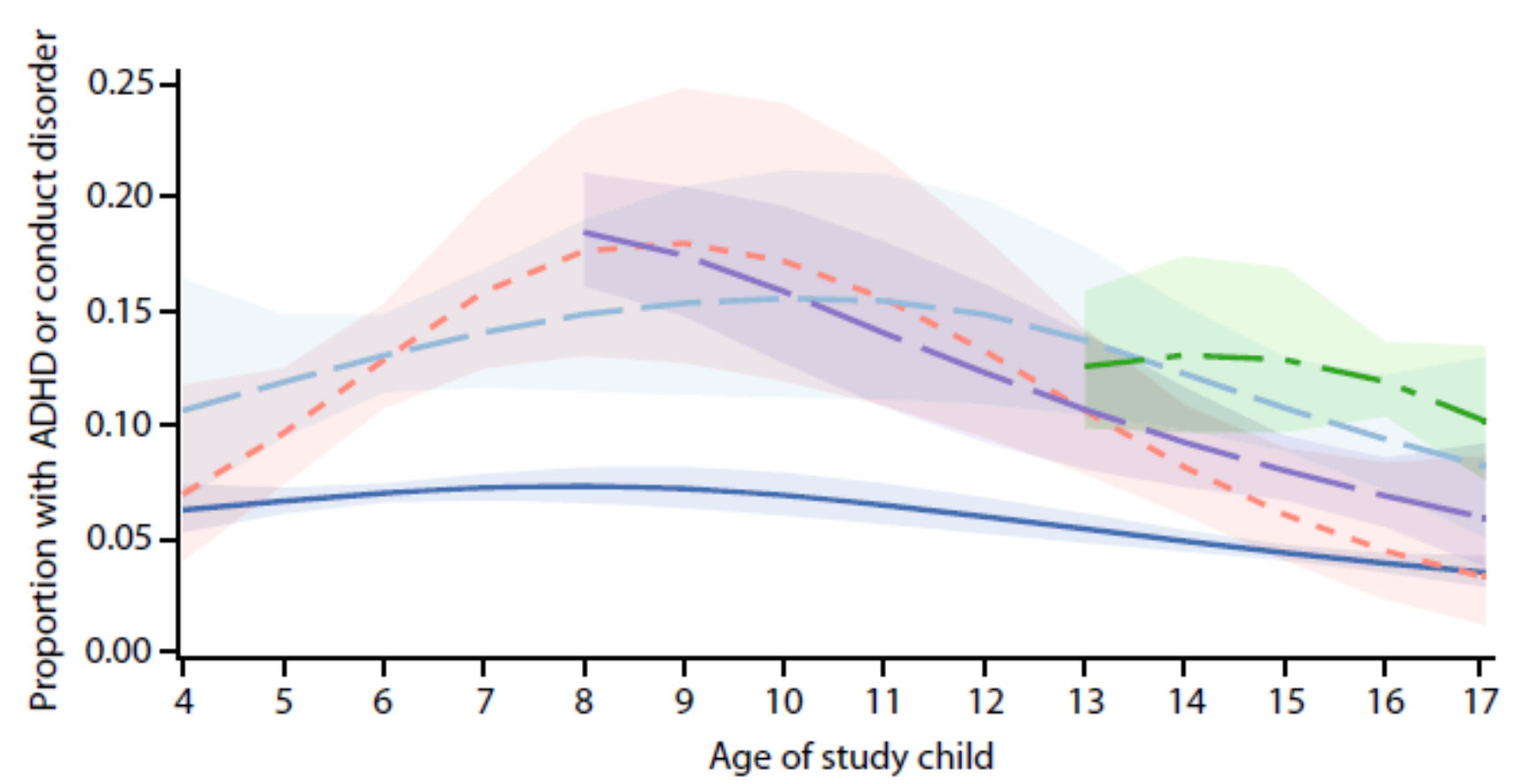

Time since separation (with $95 \%$ confidence limits)

Lives with both original parents - - - - Less than 2 years

- 2-5 years - - 5-10years

- - 10 years or more 